\title{
Positive affect and age as predictors of exercise compliance
}

Danilo Garcia, Trevor Archer

Physical exercise is linked to individuals whose affect profiles are invariably positive and it induces anti-apoptotic and anti-excitotoxic effects, buttressing blood-brain barrier intactness in both healthy individuals and those suffering from disorders accompanying overweight and obesity. In this regard, exercise offers a unique non-pharmacologic, noninvasive intervention that incorporates different regimes, whether dynamic or static, endurance, or resistance. In this brief report we present a self-report study carried out on an adolescent and adult population ( $N=280,144$ males and 136 females), which indicated that, the propensity and compliance for exercise, measured as the "Archer ratio", was predicted by positive affect. This association is discussed from the perspective of health, well-being, affect dimensions and age. 
3 Institute of Neuroscience and Physiology, Centre for Ethics, Law and Mental Health (CELAM), University of Gothenburg, Gothenburg, Sweden

5

${ }^{2}$ Network for Empowerment and Well-Being, Sweden

6

${ }^{3}$ Department of Psychology, University of Gothenburg, Gothenburg, Sweden 
7 * Correspondence concerning this article should be addressed to D. Garcia, CELAM,

8 Wallinsgatan 8, SE 43141 Mölndal, Gothenburg, Sweden. E-mail: danilo.garcia@euromail.se;

9 danilo.garcia@neuro.gu.se

10 The introduction of exercise regimes has been found beneficial both under laboratory and clinical

11 conditions; this observation is particularly evident with consideration of various health

12 biomarkers. Any bodily activity that enhances or maintains physical fitness implies the

13 involvement of regular and frequent exercise. Morris and Schoo (2004) have defined exercise as

14 a planned, structured physical activity with the purpose of improving one or more aspects of

15 physical fitness and functional capacity. Physical exercise influences cognitive, emotional,

16 learning and neurophysiological domains, both directly and indirect, thereby rendering it essential

17 that this noninvasive, non-pharmacological intervention ought to form a part of children's and

18 adolescents' long-term health programs (Archer, 2014). In juvenile and adolescent populations,

19 physical exercise holds benefits in association with the health of bones, cardiovascular fitness,

20 healthy blood lipid profiles, psychological well-being and is linked inversely to levels of

21 adiposity and stress (Loprinzi, Cardinal, Loprinzi, Lee, 2012).

22 The types of exercise relevant here have been characterized on the basis of type, intensity,

23 frequency, and duration, with either endurance or resistance capacity as the training endpoint

24 (Mougios, 2010). Endurance exercise develops one's ability to exert oneself over long periods of

25 physical activity; whereas resistance exercise implies exerting resistance to the force of muscular

26 contraction and elastic or hydraulic resistance (Ormsbee, Choi, Medlin, Geyer, Trantham, Dubis,

27 Hickner, 2009). Physical exercise has been manifested in marked improvements both in function

28 and biomarker integrity (e.g., Archer, 2011, 2013; Archer and Fredriksson, 2010; Archer and

29 Kostrzewa, 2011; Archer, Fredriksson, Schütz, Kostrzewa, 2011, Archer, Svensson, Alricsson,

30 2012; Fredriksson, Stigsdotter, Hurtig, Ewalds-Kvist, Archer, 2011). Thus, the benefits of regular 
31 physical exercise as a health-ensuring necessity over age, gender, occupation and affective status

32 cannot be overestimated (Garcia, Archer, Moradi, Andersson-Arntén, 2012; Palomo, Beninger,

33 Kostrzewa, Archer, 2008).

34 Nevertheless, the prevailing situation among youth populations suggests that these

35 benefits are largely unrealized. For instance, the 2011 Centers for Disease Control and Prevention

36 Youth Risk Behavior Surveillance System (2011) found that only $28.7 \%$ of healthy high school

37 pupils showed physical activity levels that reached the Federal guideline of 60 min moderate-to-

38 vigorous intensity physical exercise. Exercise compliance was even lesser among those

39 presenting chronic disorders, such as type I diabetes (Lukacs, Mayer, Juhasz, Varga, Foder,

40 Barkai, 2012; Maggio, Hofer, Martin, Marchand, Beghetti, Farpour-Lambert, 2010).

41 Nevertheless, there is evidence that physical exercise influences academic performance and well-

42 being positively in children and adolescents (Archer and Garcia, 2014), suggesting a strong

43 indication of its benefits on cognition and affect. Exercise compliance presents advantages, not

44 only regarding reduced stress, anxiety and depression, but also improved self-esteem and

45 psychological well-being (Dunton, Huh, Leventhal, Riggs, Hedeker, Spruijt-Metz, Pentz, 2014;

46 Garcia, Archer, Moradi, Andersson-Arntén, 2012; Gaz and Smith, 2012; Melnyk, Hrabe,

47 Szalacha, 2013).

The affective domain presents a frequently studied issue within physical exercise

49 interventions not least since the ability and capacity to interact with other individuals modulates

50 the positive interaction with oneself. Thereby placing a premium on high levels of positive affect

51 by presenting the conditions for developing personal characteristics and delivering affective

52 qualities (Heidorn and Welch, 2010). Positive and negative affect have been shown to reflect

53 stable emotional-temperamental dispositions (e.g., Watson and Clark, 1994: Tellegen, 1993). For

54 instance, one of the most used instruments to measure affect, is the Positive Affect and Negative 
55 Affect Schedule (Watson, Clark and Tellegen, 1988), which was developed on the idea that

56 positive and negative affect represent two orthogonal independent dimensions (see also Watson

57 and Tellegen, 1985). Moderate intensity physical exercise induces higher levels of positive affect

58 and lower levels of negative affect in both younger (mean 20 years) and older (mean 56 years)

59 adults (Barnett, 2013). In even older adults (65 to 95 years), both strength-based and aerobic-

60 based physical activity improved skills and mobility with concurrent improvements in mood

61 (Martins et al., 2011). In a study of both younger and older adults, 144 participants of ages

62 ranging from 19 to 93 years, assigned to a moderate intensity exercise group (15 min moderate

63 intensity cycling) or a control group (15 min rating neutral images), it was observed that exercise

64 increased high-arousal positive affect and decreased low-arousal positive affect in comparison

65 with controls (Hogan et al., 2013), as well as improving cognitive performance on a working

66 memory task. In community-dwelling older adults (over 55 years) presenting mild cognitive

67 impairment, a physical exercise intervention (SMART) was shown to improve psychological

68 well-being, cognitive functioning and quality-of-life (Gates et al., 2014). Moreover, the benefits

69 are not only at the cognitive level. For example, Östhus and colleagues (2012) studied

70 cardiovascular fitness $\left(\mathrm{VO}_{2 \max }\right)$ and endurance training in younger and older individuals. They

71 found that long-term endurance exercise training exerted a protective effect upon muscle

72 telomere length in older adults $-\mathrm{VO}_{2 \max }$ being associated positively with telomere length. In this

73 context, it is important to point out that telomeres, nucleoproteic complexes located at the ends of

74 eukaryotic chromsomes composed by non-coding repetitive sequences (McEachern et al., 2000),

75 seem to function as a mitotic 'clock', shortening progressively, the triggering of DNA damage

76 response and apoptosis (Blackburn, 2001). Finally, physical exercise programs for older adults

77 and elderly has improved dietary habits, memory for events and materials, emotional balance and

78 the enjoyment of cultural, intellectual, affective and social activities (Caprara et al., 2013). 
79 Finally, Solberg et al. (2014) obtained improvements in most measures of well-being after four

80 months of endurance training.

81 The purpose of the present study was to ascertain if affectivity and age predict compliance

82 with frequent and intensive physical exercise using self-reported data from a sample consisting of

83 Swedish high-school students and individuals employed in a number of administrative and skilled

84 labor occupations.

85

86

87 According to law $(2003: 460, \S 2)$ concerning the ethical research involving humans we arrived at

88 the conclusion that the design of the present study (e.g., all participants' data were anonymous

89 and will not be used for commercial or other non-scientific purposes) required only informed

90 consent from participants.

91 Participants and procedure

92 A total of 280 participants (144 males and 136 females) were included in the analysis. This

93 sample included high school pupils, university students, and also white-collar workers from the

94 private and public sector (age mean $=25.60 s d=12.81$ ). All participants were residents of

95 Gothenburg, Sweden. Participants were made aware that the study was anonymous, voluntary

96 and that it took 15 minutes to complete all the self-reports. First, the participants completed the

97 background questionnaire and then a battery of instruments including one measure of affect. In

98 the background questionnaire we included the measures to exercise behavior.

99 Measures

100 Exercise Behavior

101 Besides collecting demographical data (e.g., age, gender), the background questionnaire included

102 two items to measure frequency ("How often do you exercise?"; 1 = never, $5=5$ times/week or 103 more) and intensity ("Estimate the level of effort when you exercise"; $1=$ non or very low, $10=$

104 Very High) of exercise behavior.

105 Affect 
106 The Positive Affect Negative Affect Schedule (Watson, Clark \& Tellegen, 1988) allows

107 participants to respond on a 5-point Likert scale to what extent $(1=$ very slightly, $5=$ extremely $)$

108 they experienced generally the 20 adjectives encompassing 10 positive affect and 10 negative

109 affect words within the last few weeks. The positive affect subscale consists of adjectives such as

110 "strong", "proud" and "interested". The negative affect subscale consists of adjectives such as

111 "afraid", "nervous" and "ashamed". The Swedish version has been used in a wide range of

112 studies over the last decade (e.g. Garcia and Erlandsson, 2011; Nima, Rosenberg, Archer, Garcia,

113 2013; Schütz, Archer \& Garcia, 2013). In the present study Cronbach's $\alpha$ for the positive affect

114 subscale was .82 and for the negative affect subscale .86 .

115 Statistical treatment

116 The participants' answers to both exercise-items were first standardized (i.e., transformed to $z$ -

117 scores) in order to summarize them into a composite measure for exercise behavior, that is, The

118 Archer Ratio (Garcia \& Archer, 2014). A principal components analysis, with oblimin rotation,

119 suggested that a single primary factor accounted for at least $70.94 \%$ of the variance, thus

120 supporting the calculation of The Archer Ratio. Further regression analysis was conducted using

121 age, gender, positive affect and negative affect as the predictors and The Archer Ratio as the

122 outcome. A correlation analysis showed that the variables did not correlated higher that .30 , thus

123 lower than what is suggested concerning multicolliniarity (see for example Tabachnick \& Fidell,

1242007, p.88). A total of 10 participants (5\% of the total participants) had missed to answer some of

125 the questions and were therefore discarded from the analysis. The Archer Ratio has shown

126 validity by predicting actual exercise compliance in a population at a training facility (Garcia \&

127 Archer, 2014), even when compared to larger, strong, and validated scales such as The Godin-

128 Shephard Leisure-Time Physical Activity Questionnaire (Godin \& Shepard, 1985).

129

Table 1 should be here 
131 A significant model emerged $(F(4,268)=7.81, p<.001)$. Table 2 provides information about

132 regression coefficients for the predictor variables (i.e., age, gender, positive and negative affect)

133 entered predicting The Archer Ratio. Age and positive affect were the only significant predictors

134 of exercise behavior. Specifically, exercise behavior decreased with age but was positively

135 associated to positive affect.

136

137

Table 2 and Figure 1 should be here

The present study indicates that exercise compliance is positively associated with positive

138 affectivity and negatively with age. Currently, this account underlines the importance of

139 individuals' basal levels of positive affect that mobilizes the compliance and propensity for

140 exercise. Affective status, whether negative, e.g. in anorexia, or positive, e.g. as a health measure,

141 is linked with behaviors that maintain dietary habits (Engel, Wonderlich, Crosby, Mitchell, Crow,

142 Peterson et al., 2013). Regular physical exercise induces fuel utilization which mobilizes the

143 energetic cost of storing excess nutrients during relapse and alterations in circulating nutrients

144 that may modulate appetite thereby attenuating the biological drive to regain weight, involving

145 both central and peripheral aspects of energy homeostasis, may explain, in part, the utility of

146 regular activity in preventing weight regain after weight loss (Steig, Jackman, Giles, Higgins,

147 Johnson, 2011). It provides a 'scaffolding effect' that alleviates the effects of TBI (Archer, 2013)

148 and symptoms and biomarkers of depression (Archer, Josefsson, Lindwall, 2014). Exercise, in

149 this regard particularly when linked to dietary restriction, offers a cheap and practical non-

150 pharmacological, noninvasive intervention that, if introduced proactively, will provide marked

151 elements of prevention. It has been recommended that physical exercise be perceived and

152 employed in a similar manner to pharmaceutical, psychotherapy, physiotherapy and other

153 biosocio-medical interventions involving the basic and continuing education and training of

154 health care personnel and processes to assess its' needs and to prescribe and deliver it, to

155 reimburse the services and programs related to it, and to fund research on its efficacy,

156 applicability, feasibility, compliance and interactions and comparability with other preventive, 
157 therapeutic, and rehabilitative domains (Vuori, Lavie, Blair, 2013). Autophagy appears to offer

158 processes that physical exercise generates with marked health benefits involving life-span

159 expansion, protection against several disease that compromise brain function and clear benefits

160 for metabolic and bioenergetic dynamics. Accumulated evidence has underlined the premise that

161 brain neural, muscular, neuroimmune and other physiologic systems are subject to the principle

162 of "Use it-or-lose-it" intrinsic to all motor activity and exercise.

163 The present results associating positive affect but not negative affect with exercise

164 compliance are also in line with recent suggestions with regard to the etiological difference

165 between positive and negative affect. Cloninger and Garcia (2014), for example, pointed out

166 evidence (Baker, Cesa, Gatz \& Mellins, 1992) that suggest that the situational (i..e, that both

167 positive and negative affect are related to the experience of pleasant and unpleasant experiences,

168 respectively; e.g., Warr, Barter, \& Brownbridge, 1983) and dispositional explanations (i.e.,

169 positive affect has it origin in Extraversion, while negative affect arises in Neuroticism; e.g.,

170 Costa \& McCrae, 1980, 1984) of the origin of positive and negative affect do not to fit the

171 general pattern of data that has been accumulated in support of the independence of positive and

172 negative affect: a primarily situational etiology for positive affect and a primarily dispositional

173 etiology for negative affect (see also Bradburn, 1969; Diener \& Larsen, 1984; Emmons \& Diener,

174 1985). This observation led Baker and colleagues (1992) to investigate why positive and negative

175 affect are independent of each other and why they have different patterns of correlation with

176 other variables using data from twins and three-generational families. These researchers found

177 significant effects for heritability for negative affect but not for positive affect. In contrast,

178 positive affect was influenced by shared environmental effects for parents and offspring,

179 assortative mating for spouses, and shared environmental effects for the twin pairs (Baker et al.,

180 1992). Baker and colleagues (1992) concluded that "there may be important (heritable)

181 personality factors that play a critical role in determining levels of negative moods from one 
182 person to the next in the family. For positive affect, on the other hand, family resemblance is

183 explained primarily by environmental effects common to family members" (p. 162).

184 Future studies ought to focus upon the threshold levels of exercise schedules among

185 young and older people aiming at health benefits in different populations. For example, Sénéchal

186 and colleagues (2012) observed that in a study of moderate-severe metabolic syndrome, the

187 severity of disorder and age of patients were determinants of exercise intensity levels. The utility

188 of pursuing exercise programs in aging populations seems, indeed, a growing necessity.

189 "Exercise to stimulate, not to annihilate. The world wasn't formed in a day, and neither were we.

190 Set small goals and build upon them."

191 Lee Haney

192 Acknowledgement

193 We are grateful also to Sophia Garcia for excellent technical assistance and to Nick Mashkouri,

194 Markus Ekström, and Ulrika Einald for their help with the data collection.

195

196

197

198

199

200

201

202

$203 \quad$ Neurotoxic Res 18:313-327.

204 Archer T, Fredriksson A, Schütz E, Kostrzewa RM (2011b) Influence of physical exercise on

205

206

neuroimmunological functioning and health: aging and stress. Neurotoxic Res 20:69-83.

Archer T, Garcia D (2014) Physical exercise influences academic performance and well-being in

207

208

209

210

children and adolecents. Int J School Cogn Psychol DOI: 10.4172/1234-3425.1000e102.

Archer T, Kostrzewa RM (2011) Physical exercise alleviates ADHD symptoms: regional deficits

and developmental trajectory. Neurotox Res. Doi: 10.1007/s12640-011-9260-0.

Archer T, Josefsson T, Lindwall M. (2014) Effects of physical exercise on depressive symptoms

211 and biomarkers in depression. Under editorial evaluation. 
212 Baker, L. A., Cesa, I. L., Gatz, M., \& Mellins, C. (1992). Genetic and environmental influences on positive and negative affect: Support for a two-factor theory. Psychology of Aging, 7, 158-163.

Barnett F (2013) The effect of exercise on affective and self-efficacy responses in older and younger women. J Phys Act Health 10, 97-105.

Blackburn EH (2001) Switching and Signaling at the telomere. Cell 106, 661-673.

Bradburn, N. M. (1969). The structure of psychological well-being.Chicago: Aldine.

Caprara M, Molina MA, Schettini R, Santavreu M, Orosa T, Mendoza-Nunez VM, Rojas M, Fernandez-Ballesteros R (2013) Active aging promotion: results from the Vital Aging Program. Current Gerontology and Geriatric Research DOI: 10.1155/2013/817813.

Centers for Disease Control and Prevention. (2011) Youth risk behavior surveillance - United

States. MMWR Surveill Summ 61, 1-162.

Cloninger, C. R., \& Garcia, D. (2014). The Inheritance and Development of Positive Affect and Emotionality. In M. Pluess (Ed.), Genetics of Psychological Well-Being - The Role of Heritability and Genetics in Positive Psychology. New York: Oxford University Press. Under evaluation.

Costa, P. T, \& McCrae, R. R. (1980). Influence of extroversion and neuroticism on subjective well-being: Happy and unhappy people. Journal of Personality and Social Psychology, 38, 668-678.

Diener, E., \& Larsen, R. J. (1984). Temporal stability and cross-situational consistency of positive and negative affect. Journal of Personality and Social Psychology, 47, 871-883. Dunton GF, Huh J, Leventhal AM, Riggs N, Hedeker D, Spruijt-Metz D, Pentz MA (2014) Momentary assessment of affect, physical feeling states, and physical activity in children. Health Psychol 33(3):255-63. doi: 10.1037/a0032640.

Emmons, R. A., \& Diener, E. (1985). Personality correlates of subjective well-being. Personality and Social Psychology Bulletin, 11, 89-97.

Engel SG, Wonderlich SA, Crosby RD, Mitchell JE, Crow S, Peterson CB, Le Grange D, Simonich HK, Cao L, Lavender JM, Gordon KH (2013) The role of affect in the maintenance of anorexia nervosa: evidence from a naturalistic assessment of momentary behaviors and emotion. J Abnorm Psychol. 122(3):709-19. doi: 10.1037/a0034010. 
242 Fredriksson A, Stigsdotter IM, Hurtig A, Ewalds-Kvist B, Archer T (2011) Running wheel

243 activity restores MPTP-induced deficits. J Neural Transm 118:407-420.

244 Garcia, D., \& Archer, T. (2014). The Archer Ratio: A Measure of Exercise Behavior. Unpublished

245 manuscript.

246 Garcia, D., Archer, T., Moradi, S., \& Andersson-Arntén, A-C. (2012). Exercise Frequency, High

247 Activation Positive Affectivity, and Psychological Well-Being: Beyond Age, Gender, and

$248 \quad$ Occupation. Psychology, 3, 328-336. DOI: 10.4236/psych.2012.34047.

249 Garcia D, Erlandsson A (2011) The relationship between personality and subjective well-being:

250 different association patterns when measuring the affective component in frequency and

251

252

253

254

255

256

257

258

259

260

261

262

263

264

265

266

267 intensity. J Happiness Stud 12, 1023-1034. DOI: 10.1007/s10902-010-9242-6.

Gates N, Valenzuela M, Sachdev PS, Fiatarone Singh MA (2014) Psychological well-being in individuals with mild cognitive impairment. Clin Interven Aging 9, 779-792.

Gaz DV, Smith AM (2012) Psychosocial benefits and implications of exercise. Am Acad Phys Med Rehab 4, 812-817.

Godin, G. \& Shephard, R. J. (1985). A simple method to assess exercise behaviour in the community. Can J Appl Sport Sci 10, 141- 146.

Heidor B, Welch M (2010) Teaching affective qualities in physical education. Strategies: A Journal for Physical and Sport Educators, 23(5), 16-21.

Hogan CL, Mata J, Carstensen LL (2013) Exercise holds immediate benefits for affect and cognition in younger and older adults. Psychol Aging 28, 587-594, DOI: $10.1037 / \mathrm{a} 0032634$.

Loprinzi PD, Cardinal BJ, Loprinzi KL, Lee H (2012) Benefits and environmental determinants of physical activity in children and adolescents. Obes Facts 5, 597-610.

Lukacs A, Mayer K, Juhasz E, Varga B, Foder B, Barkai L (2012) Reduced physical fitness in children and adolescents with type 1 diabetes. Pediatr Diabetes 13, 432-437.

Lunn TE, Nowson CA, Worsley A, Torres SJ (2014) Does personality affect dietary intake?

268 Nutrition. 30(4):403-409. doi: 10.1016/j.nut.2013.08.012.

269 Maggio ABR, Hofer MF, Martin XE, Marchand LM, Beghetti M, Farpour-Lambert NJ (2010)

$270 \quad$ Reduced physical activity level and cardiorespiratory fitness in children with chronic 271 diseases. Eur J Pediatr 169, 1187-1193. 
272 Martins R, Coelho E, Silva M, Pindus D,Cumming S, Teixeira A, Verissimo M (2011) Effects of

273 strength and aerobic-based training on functional fitness, mood and the relationship

274 between fatness and mood in older adults. J Sports Med Phys Fitness 51, 489-496.

275 McEachern MJ, Krauskopf A, Blackburn EH (2000) Telomeres and their control. Annu Rev

$276 \quad$ Genet 34, 332-358.

277 Melnyk BM, Hrabe DP, Szalacha LA (2013) Relationships among work stress, job satisfaction,

278 mental health, and healthy lifestyle behaviors in new graduate nurses attending the nurse

279 athlete program: a call to action for nursing leaders. Nurs Adm Q 37(4):278-85. doi:

280 10.1097/NAQ.0b013e3182a2f963.

281 Morris M, \& Schoo A (2004). Optimizing exercise and physical activity in older adults.

282 Edinburgh: Butterworth Heinemann.

283 Mougios V (2010) Exercise metabolism. In: Bahrke MS (ed) Exercise biochemistry. Human

$284 \quad$ Kinetics, Champaign, p 122

285 Nima AA, Rosenberg P, Archer T, Garcia D (2013) Anxiety, Affect, Self-Esteem, and Stress:

286 Mediation and Moderation Effects on Depression.PLoSONE 8(9): e73265.

287 doi:10.1371/journal.pone.0073265.

288 Ormsbee MJ, Choi MD, Medlin JK, Geyer GH, Trantham LH, Dubis GS, Hickner RC (2009)

289 Regulation of fat metabolism during resistance exercise in sedentary lean and obese men.

$290 \quad$ J Appl Physiol 106:1529-1537.

291 Östhus IDÖ, Sgura A, Berardinelli F, Alsnes IV, Brönstad E, Rehn T, Stöbakk PK, Hatle H,

292 Wislöff U, Nauman J (2012) Telomere length and long-term endurance exercise: does

293 exercise training affect biological age? A pilot study. PLOS One 7, e52769.

294 Palomo T, Beninger RJ, Kostrzewa RM, Archer T (2008) Affective status in relation to

295 impulsiveness, motor and motivational symptoms: personality, development and physical

296 exercise. Neurotoxic Res 14, 151-168.

297 Pulgaron ER (2013) Childhood obesity: a review of increased risk for physical and psychological

298 comorbidities. Clin Ther 35, A18-A32.

299 Sénéchal M, Bouchard DR, Dionne IJ, Brochu M (2012) Lifestyle habits and physical capacity in

300 patients with moderate or severe metabolic syndrome. Metab Syndr Relat Disord.

301 10(3):232-40. doi: 10.1089/met.2011.0136. 
302 Schneiderman JU, Mennen FE, Negriff S, Trickett PK (2012) Overweight and obesity among 303 maltreated young adolescents. Child Abuse Negl 36, 370-378.

304 Schütz E, Archer T, Garcia D (2013) Character profiles and adolescents' self-reported affect. Pers $305 \quad$ Individ Diff 54, 841-844.

306 Solberg PA, Halvan H, Ommundsen Y, Hopkins WG (2014) A 1-year follow-up of effects of 307 exercise programs on well-being in older adults. A Aging Phys Act 22, 52-64. DOI: $308 \quad 10.1123 /$ japa.2012-0181.

309 Steig AJ, Jackman MR, Giles ED, Higgins JA, Johnson GC, Mahan C, Melanson EL, Wyatt HR, 310 Eckel RH, Hill JO, MacLean PS (2011) Exercise reduces appetite and traffics excess nutrients away from energetically efficient pathways of lipid deposition during the early stages of weight regain. Am J Physiol Regul Integr Comp Physiol. 2011 Sep;301(3):R656-67. doi: 10.1152/ajpregu.00212.2011.

Tabachnick, B.G., \& Fidell, L.S. (2007). Using Multivariate Statistics, Fifth Edition. Boston: Pearson Education, Inc.

Tellegen, A. (1993). Folk concepts and psychological concepts of personality and personality disorder. Psychological Inquiry, 4, 122-13

Vuori IM, Lavie CJ, Blair SN (2013) Vuori IM, Lavie CJ, Blair SN (2013) Physical activity promotion in the health care system. Mayo Clin Proc 88(12):1446-61. doi: 10.1016/j.mayocp.2013.08.020.

321 Watson, D., \& Clark, L. A. (1994). The PANAS-X: Manual for the Positive and Negative Affect 322 Schedule-Expanded Form. Ames: The University of Iowa.

323 Watson, D., Clark, L. A., \& Tellegen, A. (1988). Development and validation of brief measures of positive and negative affect: The PANAS scales. Journal of Personality and Social 325 Psychology, 54(6), 1063-1070.

326 Watson, D.. \& Tellegen. A. (1985). Toward a consensual structure of mood. Psychological Bulletin. 98. 219-235. 


\section{Table $\mathbf{1}$ (on next page)}

Correlation between age, positive affect, negative affect, and the Archer Ratio. 


\section{PeerJ Reviewing Manuscript}

Table 1. Correlation between age, positive affect, negative affect, and the Archer Ratio.

\begin{tabular}{lcccc}
\hline & Age & Positive & Negative & The Archer \\
& & Affect & Affect & Ratio \\
\hline Age & - & & & \\
Positive Affect & $.27^{* * *}$ & - & - & \\
Negative Affect & $-.30^{* * *}$ & -.04 & .03 & - \\
The Archer Ratio & $-.14^{*}$ & $.24^{* * *}$ & .03 & \\
\hline
\end{tabular}


Table 2 (on next page)

The unstandardized and standardized regression coefficients for the variables entered into the regression model as predictors of The Archer Ratio (i.e., exercise behavior). 


\section{PeerJ Reviewing Manuscript}

Table 2. The unstandardized and standardized regression coefficients for the variables entered into the regression model as predictors of The Archer Ratio (i.e., exercise behavior).

\begin{tabular}{lccccc}
\hline Predictor & $\boldsymbol{B}$ & $\boldsymbol{S E} \boldsymbol{B}$ & $\boldsymbol{\beta}$ & $\boldsymbol{t}$ & $\boldsymbol{p}$ \\
\hline Age & -.05 & .02 & -.22 & -3.22 & .001 \\
Gender & 24 & .35 & .04 & .69 & .494 \\
Positive Affect & 1.13 & .23 & .30 & 4.95 & $<.001$ \\
Negative Affect & -.11 & .24 & -.03 & -.45 & .656 \\
\hline
\end{tabular}


1

The association of positive affect in the prediction of long-term compliance in the propensity to perform physical exercise, i.e. "exercise behavior".

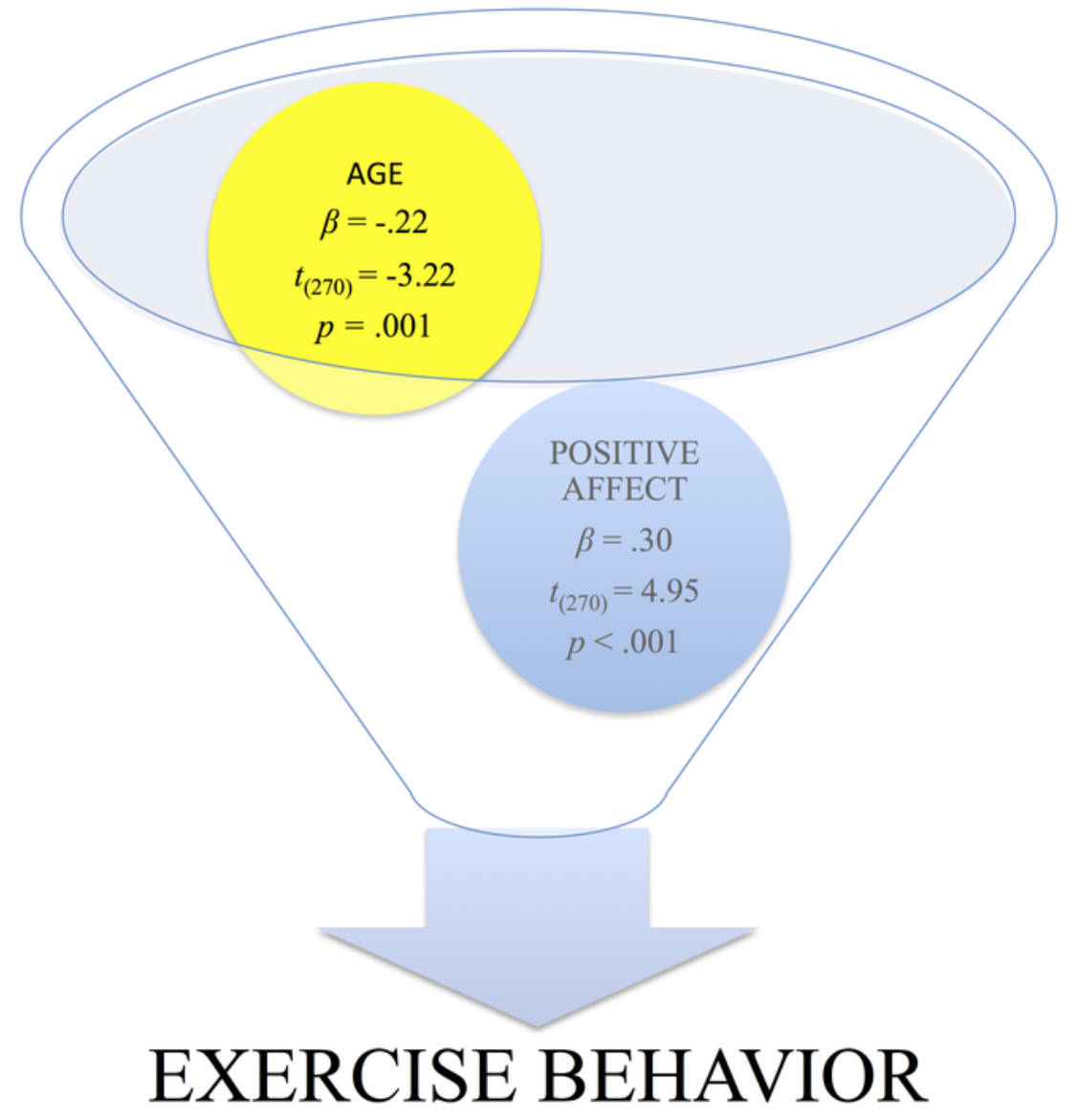

